Marquette University

e-Publications@Marquette

Biological Sciences Faculty Research and

Publications

Biological Sciences, Department of

2-25-2014

\title{
Potent Inhibition of Mandelate Racemase by a Fluorinated Substrate-Product Analogue with a Novel Binding Mode
}

\author{
Mitesh Nagar \\ Dalhousie University \\ Adam D. Lietzan \\ Marquette University, adam.lietzan@marquette.edu \\ Martin St. Maurice \\ Marquette University, martin.stmaurice@marquette.edu \\ Stephen L. Bearne \\ Dalhousie University
}

Follow this and additional works at: https://epublications.marquette.edu/bio_fac

Part of the Biology Commons

\section{Recommended Citation}

Nagar, Mitesh; Lietzan, Adam D.; Maurice, Martin St.; and Bearne, Stephen L., "Potent Inhibition of Mandelate Racemase by a Fluorinated Substrate-Product Analogue with a Novel Binding Mode" (2014).

Biological Sciences Faculty Research and Publications. 256.

https://epublications.marquette.edu/bio_fac/256 
Marquette University

e-Publications@Marquette

\section{Biological Sciences Faculty Research and Publications/College of Arts and Sciences}

This paper is NOT THE PUBLISHED VERSION; but the author's final, peer-reviewed manuscript. The published version may be accessed by following the link in the citation below.

Biochemistry, Vol. 53, No. 7 (25 February 2014): 1169-1178. DOI. This article is (C) American Chemical Society Publications and permission has been granted for this version to appear in $\underline{\mathrm{e}}$ -

Publications@Marquette. American Chemical Society Publications does not grant permission for this article to be further copied/distributed or hosted elsewhere without the express permission from American Chemical Society Publications.

\section{Potent Inhibition of Mandelate Racemase by a Fluorinated Substrate-Product Analogue with a Novel Binding Mode}

Mitesh Nagar

Department of Biochemistry and Molecular Biology, Dalhousie University, Halifax, Nova Scotia, Canada Adam D. Lietzan

Department of Biological Sciences, Marquette University, Milwaukee, Wisconsin

Martin St. Maurice

Department of Biological Sciences, Marquette University, Milwaukee, Wisconsin

Stephen L. Bearne

Department of Biochemistry and Molecular Biology, Dalhousie University, Halifax, Nova Scotia, Canada Department of Chemistry, Dalhousie University, Halifax, Nova Scotia B3H 4R2, Canada 


\section{SUBJECTS:}

Peptides and proteins, Ligands, Monomers, Crystal structure, Inhibitors

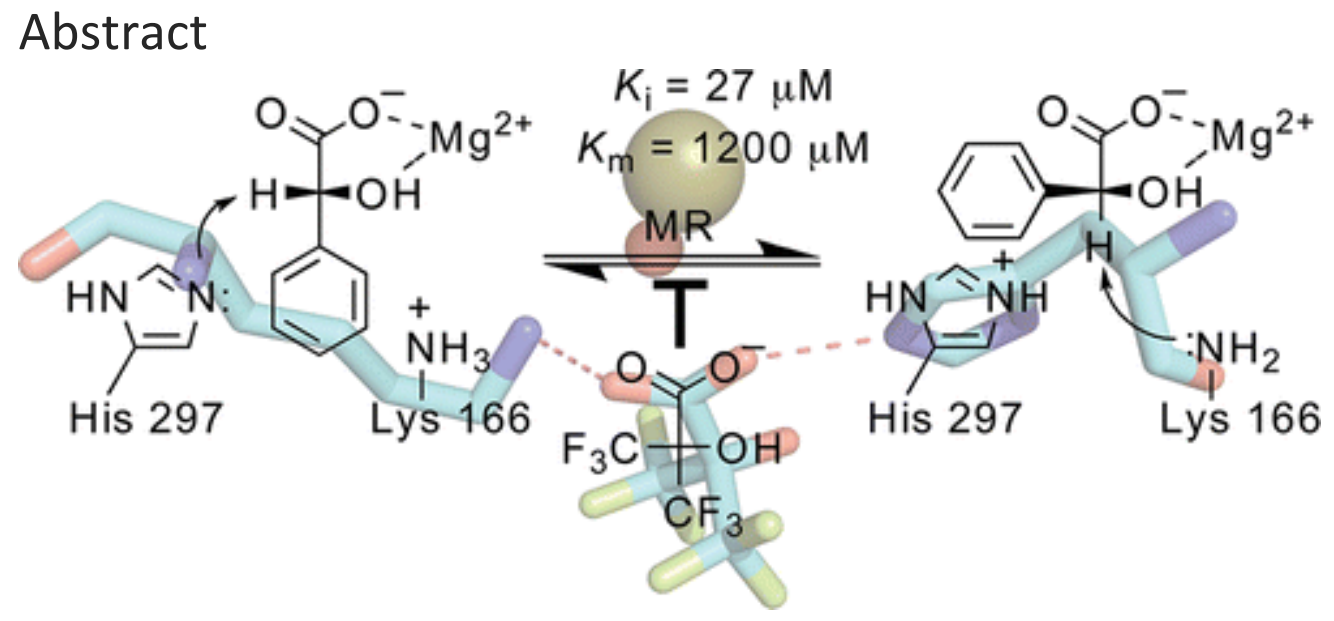

Mandelate racemase (MR) from Pseudomonas putida catalyzes the $\mathrm{Mg}^{2+}$-dependent 1,1-proton transfer that interconverts the enantiomers of mandelate. Because trifluorolactate is also a substrate of MR, we anticipated that replacing the phenyl rings of the competitive, substrate-product analogue inhibitor benzilate $\left(K_{\mathrm{i}}=0.7 \mathrm{mM}\right)$ with trifluoromethyl groups might furnish an inhibitor. Surprisingly, the substrate-product analogue 3,3,3trifluoro-2-hydroxy-2-(trifluoromethyl)propanoate (TFHTP) was a potent competitive inhibitor $\left[K_{\mathrm{i}}=27 \pm 4 \mu \mathrm{M}\right.$; cf. $K_{\mathrm{m}}=1.2 \mathrm{mM}$ for both $(R)$-mandelate and $(R)$-trifluorolactate]. To understand the origins of this high binding affinity, we determined the X-ray crystal structure of the MR-TFHTP complex to $1.68 \AA$ resolution. Rather than chelating the active site $\mathrm{Mg}^{2+}$ with its glycolate moiety, like other ground state analogues, TFHTP exhibited a novel binding mode with the two trifluoromethyl groups closely packed against the 20s loop and the carboxylate bridging the two active site Brønsted acid-base catalysts Lys 166 and His 297. Recognizing that positioning a carboxylate between the Brønsted acid-base catalysts could yield an inhibitor, we showed that tartronate was a competitive inhibitor of MR $\left(K_{\mathrm{i}}=1.8 \pm 0.1 \mathrm{mM}\right)$. The X-ray crystal structure of the MR-tartronate complex $(1.80$ $\AA$ 住olution) revealed that the glycolate moiety of tartronate chelated the $\mathrm{Mg}^{2+}$ and that the carboxylate bridged Lys 166 and His 297. Models of tartronate in monomers A and B of the crystal structure mimicked the binding orientations of $(S)$-mandelate and that anticipated for $(R)$-mandelate, respectively. For the latter monomer, the 20s loop appeared to be disordered, as it also did in the X-ray structure of the MR triple mutant (C92S/C264S/K166C) complexed with benzilate, which was determined to $1.89 \AA$ resolution. These observations indicate that the 20s loop likely undergoes a significant conformational change upon binding $(R)$-mandelate. In general, our observations suggest that inhibitors of other enolase superfamily enzymes may be designed to capitalize on the recognition of the active site Brønsted acid-base catalysts as binding determinants.

Mandelate racemase (MR, EC 5.1.2.2) from Pseudomonas putida catalyzes the $\mathrm{Mg}^{2+}$-dependent 1,1-proton transfer that interconverts the enantiomers of mandelate via a two-base mechanism with His 297 and Lys 166 abstracting the $\alpha$-proton from $(R)$-mandelate and $(S)$-mandelate, respectively, as shown in Scheme 1.(1) MR is very proficient at discriminating between the substrate in the ground state and the altered substrate in the transition state, binding the latter species with an association constant equal to $5 \times 10^{18} \mathrm{M}^{-1}$ and stabilizing the transition state of the reaction by $26 \mathrm{kcal} / \mathrm{mol} .(2,3)$ Consequently, MR has been studied as a paradigm for enzymes that catalyze rapid carbon-hydrogen bond cleavage of carbon acids with relatively high $\mathrm{p} K_{\mathrm{a}}$ values.(1) Recently, we demonstrated that $\beta, \gamma$-unsaturation is not a necessary requirement for catalysis and that MR is capable of catalyzing the racemization of the enantiomers of 3,3,3-trifluorolactate (TFL). 
Although $k_{\text {cat }}$ for this substrate was reduced by $\sim 100$-fold relative to that of mandelate as a substrate, the values of $K_{\mathrm{m}}$ were 1.7 and $1.2 \mathrm{mM}$ for $(S)$ - and $(R)$-TFL, respectively, similar to the corresponding values of 1.2 and 1.0 $\mathrm{mM}$ observed for $(R)$ - and $(S)$-mandelate, respectively.(4) The fact that MR bound TFL with an affinity similar to that exhibited for mandelate was unexpected considering that MR binds lactate with low affinity $\left(K_{\mathrm{i}} \approx 30\right.$ $\mathrm{mM}$ ).(5) Indeed, the binding affinity that MR exhibits for TFL exceeds that expected on the basis of hydrophobic effects alone.(4)

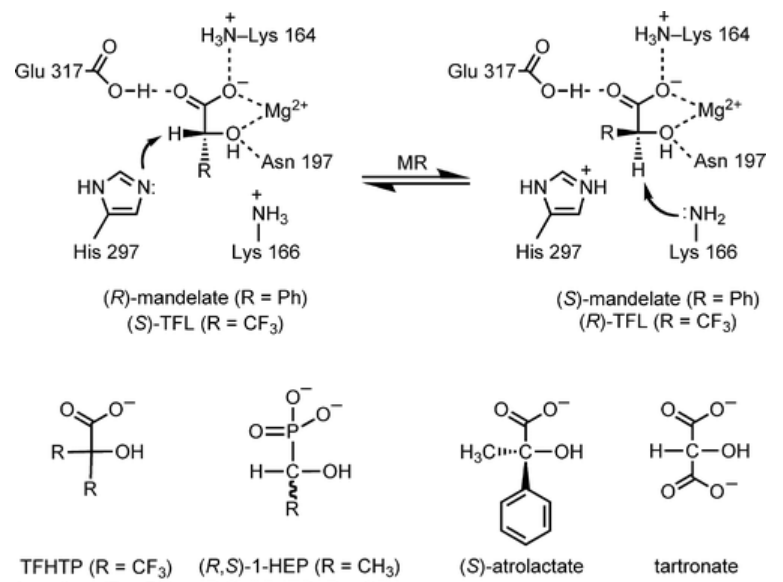

Scheme 1. Reaction Catalyzed by Mandelate Racemase (MR) and Structures of Inhibitors Discussed in the Text

Previously, we observed that the substrate-product analogue benzilate $\left(K_{\mathrm{i}}=0.67 \mathrm{mM}\right)$ is a competitive inhibitor of MR, binding with an affinity that is similar to that exhibited for mandelate.(6) Consequently, we rationalized that an inhibitor of MR might be generated by replacing the phenyl rings of benzilate with trifluoromethyl groups. Herein, we describe the potent inhibition of MR by the substrate-product analogue 3,3,3-trifluoro-2hydroxy-2-(trifluoromethyl)propanoate (TFHTP). Surprisingly, the X-ray crystal structure of MR with bound TFHTP reveals that the inhibitor is bound with an orientation that differs markedly from the binding orientation observed previously for the substrate,(7) analogues of the substrate,(8-11) and intermediate analogues.(12) Interestingly, the higher binding affinity of TFHTP arises, in part, because the carboxylate group forms a salt bridge between the Brønsted acid-base catalysts His 297 and Lys 166. Recognition of this novel binding mode led to our subsequent identification of tartronic acid as an inhibitor of MR. We show that the glycolate moiety of tartronic acid chelates the $\mathrm{Mg}^{2+}$ ion within the active site in a manner similar to that of mandelate, while the second carboxylate bridges the two Brønsted acid-base catalysts in a manner similar to that of TFHTP.

\section{Materials and Methods}

\section{General}

Tartronic acid was purchased from Alfa Aesar (Ward Hill, MA). (R)-Mandelic acid, a-hydroxyisobutyric acid, 3,3,3trifluoro-2-hydroxy-2-(trifluoromethyl)propanoic acid, and all other reagents, unless mentioned otherwise, were purchased from Sigma-Aldrich Canada Ltd. (Oakville, ON). Nuclear magnetic resonance (NMR) analyses were conducted at the Nuclear Magnetic Resonance Research Resource (NMR-3) using either a Brüker/Tecmag AC250 spectrometer, a Brüker AV-300 spectrometer, or a Brüker AV-500 spectrometer. Chemical shifts $(\delta)$ for proton $\left({ }^{1} \mathrm{H}\right)$, carbon $\left({ }^{13} \mathrm{C}\right)$, and phosphorous $\left({ }^{31} \mathrm{P}\right)$ spectra are reported in parts per million relative to the HOD signal for spectra obtained in $\mathrm{D}_{2} \mathrm{O}$. High-resolution (HR) electrospray ionization (ESI) mass spectra (MS) were recorded using a Brüker microTOF Focus orthogonal ESI-TOF mass spectrometer instrument operating in either 
positive or negative ion mode. Circular dichroism (CD) assays were conducted using a JASCO (Easton, MD) J-810 spectropolarimeter with a jacketed cell holder. Melting points are uncorrected.

\section{$(R, S)$-1-Hydroxy-2,2,2-trifluoroethylphosphonate (TFHEP)}

The ethyl groups were removed from diethyl 1-hydroxy-2,2,2-trifluoroethylphosphonate by treatment with trimethylsilylbromide using a procedure similar to that described by Freeman et al.(13) Diethyl 1-hydroxy-2,2,2trifluoroethylphosphonate $(1.0 \mathrm{~g}, 4.24 \mathrm{mmol})$ was dissolved in $10 \mathrm{~mL}$ of dry acetonitrile. Trimethylsilylbromide ( $2.63 \mathrm{~mL}, 20.4 \mathrm{mmol}, 4.8$ equiv) was added dropwise to the solution. The solution was refluxed for $1 \mathrm{~h}$ under an atmosphere of argon, and the solvent was removed using rotary evaporation under reduced pressure to yield a slightly yellow liquid. Dioxane $(3.4 \mathrm{~mL})$, water $(3.4 \mathrm{~mL})$, and cyclohexylamine $(1.6 \mathrm{~mL})$ were added, and the solution was stirred for $1 \mathrm{~h}$. After removal of the solvent using rotary evaporation, a white powder remained. This was dissolved in water $(16 \mathrm{~mL})$, and the solution was filtered. Acetone $(150 \mathrm{~mL})$ was added, and a white precipitate, the cyclohexylamine salt, formed upon sitting.(14) After being cooled for $1 \mathrm{~h}$ at $4{ }^{\circ} \mathrm{C}$, the precipitate was collected using suction filtration. The cyclohexylamine salt was then converted to the sodium salt by passing it through a column containing $\mathrm{AG} 50 \mathrm{~W}-\mathrm{X} 8$ ( $\mathrm{Na}^{+}$form). The eluent was collected, and lyophilization yielded a white powder (0.85 g, 90\%): $\mathrm{mp} 238-241{ }^{\circ} \mathrm{C}$ (crystal became opaque at $90{ }^{\circ} \mathrm{C}$ ); ${ }^{1} \mathrm{H}$ NMR $\left(500 \mathrm{MHz}, \mathrm{D}_{2} \mathrm{O}\right) \delta 4.12$ (m); ${ }^{13} \mathrm{C}$ NMR (63 MHz, $\mathrm{D}_{2} \mathrm{O},{ }^{1} \mathrm{H}$-decoupled) $\delta 67.60\left(\mathrm{dq},{ }^{1} \mathrm{~J}_{\mathrm{C}, \mathrm{P}}=151.3 \mathrm{~Hz},{ }^{2} J_{\mathrm{C}, \mathrm{F}}=30.6 \mathrm{~Hz}, \mathrm{CH}\right), 124.61\left(\mathrm{qd},{ }^{1} \mathrm{~J}_{\mathrm{C}, \mathrm{F}}=\right.$ $\left.280.9 \mathrm{~Hz},{ }^{2} \mathrm{~J}_{\mathrm{C}, \mathrm{P}}=5.6 \mathrm{~Hz}, \mathrm{CF}_{3}\right) ;{ }^{31} \mathrm{P}$ NMR (101 MHz, $\mathrm{D}_{2} \mathrm{O},{ }^{1} \mathrm{H}$-decoupled) $\delta 11.88$ (q, ${ }^{3} J_{\mathrm{F}, \mathrm{P}}=7.43 \mathrm{~Hz}$ ); ${ }^{19} \mathrm{~F} \mathrm{NMR}(235$ $\left.\mathrm{MHz}, \mathrm{D}_{2} \mathrm{O}\right) \delta-71.08\left(\mathrm{dd},{ }^{3} \mathrm{~J}_{\mathrm{F}, \mathrm{H}}=15.30 \mathrm{~Hz},{ }^{3} \mathrm{~J}_{\mathrm{F}, \mathrm{P}}=7.43 \mathrm{~Hz}\right.$ ); HRMS $\left(\mathrm{ESI}^{-}\right) \mathrm{m} / \mathrm{z}$ calcd for $\mathrm{C}_{2} \mathrm{H}_{3} \mathrm{~F}_{3} \mathrm{O}_{4} \mathrm{P}\left[\mathrm{M}-\mathrm{H}^{-} 178.9721\right.$, found 178.9735 .

\section{$(R, S)$-1-Hydroxyethylphosphonate (1-HEP)}

Synthesis of dimethyl 1-hydroxyethylphosphonate was conducted as described by Chen et al.(15) Dimethyl phosphate $(1.10 \mathrm{~g}, 10 \mathrm{mmol})$ and acetaldehyde $(0.44 \mathrm{~g}, 10 \mathrm{mmol})$ were stirred together for $10 \mathrm{~min}$ at room temperature, followed by addition of potassium fluoride and basic alumina (1:1 mass ratio, $3 \mathrm{~g}$ each). After the mixture had been stirred for an additional $30 \mathrm{~min}$, methylene chloride $(15 \mathrm{~mL})$ was added and the resulting suspension was filtered. From the filtrate, methylene chloride was evaporated under reduced pressure, leaving $0.68 \mathrm{~g}$ of dimethyl 1-hydroxyethylphosphonate as a viscous yellow liquid. The methyl groups were removed from dimethyl 1-hydroxyethylphosphonate by treatment with trimethylsilylbromide using a procedure similar to that described by Freeman et al.(13) Dimethyl 1-hydroxyethylphosphonate $(0.49 \mathrm{~g}, 3.2 \mathrm{mmol})$ was dissolved in dry acetonitrile $(10 \mathrm{~mL})$. Trimethylsilylbromide $(2.26 \mathrm{~mL}, 17.5 \mathrm{mmol}, 5.0$ equiv) was added dropwise to the solution. The solution was refluxed for $1 \mathrm{~h}$ under an atmosphere of argon, and the solvent was removed using rotary evaporation under reduced pressure to yield a slightly yellow liquid. Dioxane $(3.4 \mathrm{~mL})$, water $(3.4 \mathrm{~mL})$, and cyclohexylamine $(1.6 \mathrm{~mL})$ were added, and the solution was stirred for $1 \mathrm{~h}$ at room temperature. After removal of the solvent using rotary evaporation, a slightly yellow liquid was obtained. This was dissolved in water (16 $\mathrm{mL})$, and then acetone $(150-250 \mathrm{~mL}$ ) was added until the cyclohexylamine salt formed as a white precipitate. After being cooled overnight at $4{ }^{\circ} \mathrm{C}$, the precipitate was collected using suction filtration. The cyclohexylamine salt was then converted to the sodium salt by passing it through a column containing AG $50 \mathrm{~W}-\mathrm{X} 8$ ( $\mathrm{Na}^{+}$form). Fractions containing phosphonate were pooled and lyophilized to obtain the sodium salt of 1hydroxyethylphosphonate as a white powder (0.224 g, 41\%): $\mathrm{mp} 223-225{ }^{\circ} \mathrm{C} ;{ }^{1} \mathrm{H} N M R\left(\mathrm{D}_{2} \mathrm{O}, 500 \mathrm{MHz}\right) \delta 1.23$ $\left(\mathrm{dd},{ }^{3} J_{\mathrm{H}, \mathrm{H}}=7.1 \mathrm{~Hz},{ }^{3} \mathrm{H}_{\mathrm{H}, \mathrm{P}}=15.9 \mathrm{~Hz}, 3 \mathrm{H}, \mathrm{CH}_{3}\right), 3.74\left(\mathrm{dq},{ }^{3} \mathrm{~J}_{\mathrm{H}, \mathrm{H}}=7.1 \mathrm{~Hz},{ }^{2} J_{\mathrm{H}, \mathrm{P}}=5.9 \mathrm{~Hz}, 1 \mathrm{H}, \mathrm{OCHP}\right) ;{ }^{13} \mathrm{C} \mathrm{NMR}\left(\mathrm{D}_{2} \mathrm{O}, 126\right.$ $\mathrm{MHz},{ }^{1} \mathrm{H}$-decoupled) $\delta 17.10\left(\mathrm{CH}_{3}\right), 64.72\left(\mathrm{~d},{ }^{1} \mathrm{~J}_{\mathrm{C}, \mathrm{P}}=157.9 \mathrm{~Hz}, \mathrm{OCHP}\right) ;{ }^{31} \mathrm{P}$ NMR $\left(\mathrm{D}_{2} \mathrm{O}, 202 \mathrm{MHz},{ }^{1} \mathrm{H}\right.$-decoupled) $\delta$ 20.94; ${ }^{31} \mathrm{P}$ NMR $\left(\mathrm{D}_{2} \mathrm{O}, 202 \mathrm{MHz},{ }^{1} \mathrm{H}\right.$-coupled) $\delta 20.94\left(\mathrm{dq},{ }^{2} \mathrm{~J}_{\mathrm{H}, \mathrm{P}}=5.91 \mathrm{~Hz},{ }^{3} \mathrm{~J}_{\mathrm{H}, \mathrm{P}}=15.90 \mathrm{~Hz}\right.$ ); HRMS $\left.(\mathrm{ESI})^{+}\right) \mathrm{m} / z$ calcd for $\mathrm{C}_{2} \mathrm{H}_{6} \mathrm{Na}_{2} \mathrm{O}_{4} \mathrm{P}[\mathrm{M}+\mathrm{H}]^{+}$170.9799, found 170.9800 . 


\section{Concentration Correction for TFHEP and 1-HEP}

${ }^{1} \mathrm{H}$ NMR spectroscopy was used to correct for the presence of waters of hydration and sodium ion stoichiometry and thereby permit accurate estimation of the concentration of TFHEP and 1-HEP in solution. Equimolar solutions ( $20 \mathrm{mM}$ based on the theoretical molecular weight) of 1-HEP $(170.01 \mathrm{~g} / \mathrm{mol})$ or TFHEP $(223.98 \mathrm{~g} / \mathrm{mol})$ and sodium acetate were prepared in $5 \mathrm{~mL}$ of $\mathrm{D}_{2} \mathrm{O} .{ }^{1} \mathrm{H}$ NMR spectra for these solutions were obtained, and integrated signal intensities corresponding to the $\alpha-\mathrm{H}$ and $\alpha-\mathrm{CH}_{3}$ of $1-\mathrm{HEP}$ and the $\alpha-\mathrm{H}$ of TFHEP were calculated with reference to the signal intensities of the methyl protons of the sodium acetate internal standard. The actual concentrations of 1-HEP and TFHEP were then calculated from the ratio of signal intensities and the known concentration of sodium acetate.

\section{Site-Directed Mutagenesis}

The C92S/C264S/K166C triple mutant of MR (tmMR) was constructed by performing three rounds of polymerase chain reaction-based site-directed mutagenesis using the QuikChange Site-Directed Mutagenesis Kit (Stratgene, La Jolla, CA) and following the protocols described by the manufacturer. The pET52b(+)-wtMR plasmid(16) was used as a template to create the C264S MR mutant plasmid, which was then used as a template in the next round of site-directed mutagenesis to create a double-mutant C92S/C264S MR plasmid. Finally, the K166C mutation was introduced to generate tmMR using the double-mutant plasmid as the template. Reactions were conducted using PfuTurbo DNA polymerase (Bio Basic Inc., Markham, ON). The forward (F) and reverse (R) synthetic deoxyoligonucleotide primers used to construct the mutants were $5^{\prime}$ -

CGCAAAACGCTTCAGCCTGGCAGGTTATACGGG-3' (F, C92S), 5'-CCCGTATAACCTGCCAGGCTGAAGCGTTTTGCG-3' (R, C92S), 5'-GCATTGAGCATCGGTGCAAGCCGGTTGGCTATGCC-3' (F, C264S), 5'GGCATAGCCAACCGGCTTGCACCGATGCTCAATGC-3' (R, C264S), 5'-GCGGTTAAGACCTGCATCGGCTATCCGGC-3' (F, K166C), and 5'-GCCGGATAGCCGATGCAGGTCTTAACCGC-3' (R, K166C). The codons specifying the relevant amino acids are underlined, and the altered bases are shown in bold. Potential mutant plasmids were used to transform competent Escherichia coli DH5 $\alpha$ cells. DH5 $\alpha$ cells were used for plasmid maintenance and for all sequencing reactions. After each round of site-directed mutagenesis, the mutant open reading frame was sequenced using commercial automated DNA sequencing (Robarts Research Institute, London, ON) to ensure that no other alterations of the nucleotide sequence had been introduced. For X-ray crystallography studies, tmMR was overexpressed in and purified from E. coli BL21(DE3) cells as described previously for wild-type MR.(12) Replacement of Cys 92 and Cys 264 with Ser residues did not significantly alter the activity of the enzyme (M. Nagar and S. L. Bearne, unpublished observations).

\section{Enzyme Purification}

Recombinant MR from $P$. putida was overproduced in and purified from E. coli BL21(DE3) cells transformed with the $\mathrm{pET}-52 \mathrm{~b}(+)$-wtMR plasmid, a pET-52b(+) plasmid (Novagen, Madison, WI) containing the MR open reading frame.(16) This construct encodes the MR gene product (MASWSHPQFEKGALEVLFQGPGYHM $1 . . . M R$ ) as a fusion protein with an $\mathrm{N}$-terminal Strepll tag (underlined; $\mathrm{M}_{1}$ represents the first amino acid of wild-type MR). The enzyme was purified by affinity chromatography using Strep-Tactin Superflow resin (IBA GmbH, Göttingen, Germany) as described previously.(16) Upon elution from the column, the enzyme was dialyzed against storage buffer \{HEPES buffer (100 mM, pH 7.5) containing $\mathrm{MgCl}_{2}(3.3 \mathrm{mM}), \mathrm{NaCl}(200 \mathrm{mM})$, and glycerol [10\% (v/v)]\} and stored at $-20^{\circ} \mathrm{C}$. The purity of the enzyme preparation $(\geq 99 \%)$ was checked using $12 \%$ sodium dodecyl sulfatepolyacrylamide gel electrophoresis. The tag was not removed from the enzyme.

\section{Enzyme Assays}

MR activity was assayed using a CD-based assay by following the change in ellipticity of mandelate at $262 \mathrm{~nm}$ with a $1 \mathrm{~cm}$ light path (unless otherwise indicated) as described by Sharp et al.(17) All kinetic assays, including inhibition experiments with TFHEP, 1-HEP, TFHTP, tartronate, and $\alpha$-hydroxyisobutyrate, were conducted at 25 
${ }^{\circ} \mathrm{C}$ in $\mathrm{Na}^{+}$-HEPES buffer $(0.1 \mathrm{M}, \mathrm{pH} 7.5)$ containing $\mathrm{MgCl}_{2}(3.3 \mathrm{mM})$ and bovine serum albumin (BSA, $\left.0.005 \%\right)$. The concentration of $(R)$-mandelate for assays ranged from 0.25 to $20.0 \mathrm{mM}$. The concentrations of the inhibitors and MR used were as follows: $0.81,1.62$, and $3.24 \mathrm{mM}$ TFHEP $(150.72 \mathrm{ng} / \mathrm{mL}$; using a cuvette with a $0.5 \mathrm{~cm}$ light path for $3.24 \mathrm{mM}$ TFHEP), 16.37, 32.74, and $65.49 \mathrm{mM}$ 1-HEP $(122.4 \mathrm{ng} / \mathrm{mL}$; using a cuvette with a $0.5 \mathrm{~cm}$ light path), $0.02,0.05$, and $0.10 \mathrm{mM} \mathrm{TFHTP}(129.8 \mathrm{ng} / \mathrm{mL}), 0.75,1.50$, and $3.00 \mathrm{mM}$ tartronate $(131.45 \mathrm{ng} / \mathrm{mL})$, and $3.5,7.0$, and $14.0 \mathrm{mM} \alpha$-hydroxyisobutyrate $(141.55 \mathrm{ng} / \mathrm{mL}$; using a cuvette with a $0.5 \mathrm{~cm}$ light path). The apparent kinetic constants $V_{\max }$ and $K_{\mathrm{m}}$ were determined by fitting the initial velocity data to eq 1 using nonlinear regression analysis and KaleidaGraph version 4.02 from Synergy Software (Reading, PA)

$$
v_{\mathrm{i}}=\frac{\mathrm{V}_{\max }[\mathrm{S}]}{K_{\mathrm{m}}+[\mathrm{S}]}
$$

(1)

Competitive inhibition constants $\left(K_{\mathrm{i}}\right)$ were determined from plots of the apparent $K_{\mathrm{m}} / V_{\max }$ values versus inhibitor concentration in accord with eq $2 .(18)$

$$
v_{\mathrm{i}}=\frac{\mathrm{V}_{\max }[\mathrm{S}]}{K_{\mathrm{m}}\left(1+\frac{[\mathrm{I}]}{K_{\mathrm{i}}}\right)+[\mathrm{S}]}
$$

(2)

All kinetic parameters were determined in triplicate, and average values are reported. The reported errors are standard deviations. The concentration of wild-type MR was determined from its absorbance at $280 \mathrm{~nm}$ using an extinction coefficient of $53400 \mathrm{M}^{-1} \mathrm{~cm}^{-1}$, which was calculated using the ProtParam tool available on the ExPASy server (http://web.expasy.org/protparam).(19)

\section{Protein Crystallization}

Crystals were grown by the hanging-drop vapor diffusion method against a reservoir volume of $500 \mu \mathrm{L}$. The protein solution and reservoir solution were mixed in a 1:1 ratio to a final volume of $4 \mu \mathrm{L}$. Crystals grew spontaneously at $21^{\circ} \mathrm{C}$ and $\sim 50 \%$ humidity.

\section{Cocrystallization of MR with TFHTP}

For the MR crystals grown in the presence of TFHTP, the reservoir solution consisted of PEG 1500 [20\% (w/v)], glycine $(120 \mathrm{mM}), \mathrm{KNO}_{3}(70 \mathrm{mM})$, and Tris- $\mathrm{HCl}$ buffer $(100 \mathrm{mM}, \mathrm{pH} 8.0)$. The protein solution consisted of 5.9 $\mathrm{mg} / \mathrm{mL}$ MR purified as described above, $\mathrm{MgCl}_{2}(3.3 \mathrm{mM})$, TFHTP $(1 \mathrm{mM})$, and HEPES buffer $(50 \mathrm{mM}, \mathrm{pH}$ 7.5). The resulting cubelike crystals $(\sim 100 \mu \mathrm{m} \times 60 \mu \mathrm{m} \times 50 \mu \mathrm{m})$ grew to full size within 10-20 days. Crystals were harvested and transferred to a synthetic stabilizing solution consisting of PEG 1500 [24\% (w/v)], glycine (132 $\mathrm{mM}), \mathrm{KNO}_{3}(70 \mathrm{mM})$, TFHTP $(1 \mathrm{mM})$, and Tris- $\mathrm{HCl}$ buffer $(80 \mathrm{mM}, \mathrm{pH} 8.0)$. These stabilized crystals were equilibrated in the synthetic stabilizing solution for 5-10 min and then were transferred directly to a cryoprotectant solution consisting of PEG 1500 [40\% (w/v)], glycine (138 mM), KNO 3 (70 mM), TFHTP (1 mM), and Tris- $\mathrm{HCl}$ buffer $(100 \mathrm{mM}, \mathrm{pH} 8.0)$. The cryoprotected crystals were flash-cooled in a nitrogen gas stream at $100 \mathrm{~K}$.

\section{Cocrystallization of $M R$ with Tartronate}

For the MR crystals grown in the presence of tartronate, the reservoir solution consisted of PEG 1500 [14\% $(\mathrm{w} / \mathrm{v})]$, glycine $(100 \mathrm{mM})$, and triethanolamine buffer $(100 \mathrm{mM}, \mathrm{pH}$ 8.5). The protein solution consisted of 6.0 
$\mathrm{mg} / \mathrm{mL}$ MR purified as described above, $\mathrm{MgCl}_{2}(3.3 \mathrm{mM})$, sodium tartronate $(20 \mathrm{mM})$, and HEPES buffer ( $50 \mathrm{mM}$, $\mathrm{pH}$ 7.5). The resulting cubelike crystals $(\sim 70 \mu \mathrm{m} \times 70 \mu \mathrm{m} \times 50 \mu \mathrm{m})$ grew to full size within 20-30 days.

Approximately 50 days after crystallization had been initiated, the crystals were harvested and transferred to a synthetic stabilizing solution consisting of PEG 1500 [19\% (w/v)], glycine (110 mM), sodium tartronate (20 mM, $\mathrm{pH} 7.5)$, and triethanolamine buffer $(100 \mathrm{mM}, \mathrm{pH} 8.5)$. These stabilized crystals were equilibrated in the synthetic stabilizing solution for 5-10 min and then were transferred directly to a cryoprotectant solution consisting of PEG 1500 [39.5\% (w/v)], glycine $(110 \mathrm{mM})$, sodium tartronate $(20 \mathrm{mM})$, and triethanolamine buffer (100 mM, pH 8.5). After being equilibrated in the cryoprotectant solution for $7 \mathrm{~min}$, the crystals were flashcooled in a nitrogen gas stream at $100 \mathrm{~K}$.

\section{Cocrystallization of tmMR with Benzilate}

Crystals of the MR triple mutant (C92S/C264S/K166C, tmMR) were grown in the presence of benzilate. The reservoir solution consisted of PEG 1500 [15\% (w/v)], glycine (150 mM), NaCl (50 mM), and HEPES buffer (100 $\mathrm{mM}, \mathrm{pH} 7.5)$, and the protein solution consisted of $6.6 \mathrm{mg} / \mathrm{mL} \mathrm{tmMR}$ purified as described above, $\mathrm{MgCl}_{2}(3.3$ $\mathrm{mM})$, benzilate $(20 \mathrm{mM})$, and HEPES buffer $(50 \mathrm{mM}, \mathrm{pH} 7.5)$. The resulting cubelike crystals $(\sim 160 \mu \mathrm{m} \times 90 \mu \mathrm{m} \times$ $120 \mu \mathrm{m})$ grew to full size within 10-20 days. Crystals were harvested and transferred directly to a synthetic stabilizing solution consisting of PEG 1500 [24\% (w/v)], glycine (165 mM), sodium tartronate $(20 \mathrm{mM}), \mathrm{NaCl}(50$ $\mathrm{mM})$, and HEPES buffer ( $80 \mathrm{mM}, \mathrm{pH} 7.5)$. These stabilized crystals were subsequently transferred to a solution containing PEG 1500 [42\% (w/v)], glycine $(175 \mathrm{mM})$, benzilate $(20 \mathrm{mM}), \mathrm{NaCl}(60 \mathrm{mM})$, and HEPES buffer $(100$ $\mathrm{mM}, \mathrm{pH} 7.5)$, incubated for $5 \mathrm{~min}$, and then flash-cooled in a nitrogen gas stream at $100 \mathrm{~K}$.

\section{Data Collection, Structure Determination, and Refinement}

X-ray diffraction data for MR cocrystallized with tartronate were collected at Advanced Photon Source (APS) beamline LS-CAT-21-ID-G on a Rayonix MarMosaic 300 CCD detector, with an X-ray wavelength of $0.979 \AA$ A. X-ray diffraction data for MR cocrystallized with TFHTP were collected at APS beamline LS-CAT-21-ID-D on a Rayonix MarMosaic 300 CCD detector, with an X-ray wavelength of $1.13 \AA$. X-ray diffraction data for tmMR cocrystallized with benzilate were collected at APS beamline LS-CAT-21-ID-F on a Rayonix MarMosaic 225 CCD detector, with an X-ray wavelength of $0.979 \AA$. Diffraction images were processed using HKL2000.(20) The structures were determined by molecular replacement using the wild-type MR enzyme [Protein Data Bank (PDB) entry 2MNR] as the search model with Phaser.(21) The molecular replacement models were extended by several rounds of manual model building with COOT(22) and refinement with REFMAC(23) using a geometric/X-ray weighting term of 0.2. Noncrystallographic restraints between each monomer were applied for the first round of refinement but were relieved for subsequent rounds. Water molecules were added to the model in COOT with subsequent manual verification. Ligand coordinates for TFHTP were generated and optimized for structure refinement using eLBOW (electronic ligand building and optimization workbench).(24) Data collection and processing statistics are listed in Table 1.

Table 1. Data Collection and Refinement Statisticsa

\begin{tabular}{|l|l|l|l|}
\hline & MR and tartronate & MR and TFHTP & tmMR and benzilate \\
\hline PDB entry & $4 \mathrm{M} 6 \mathrm{U}$ & 4FP1 & 4HNC \\
\hline space group & 1422 & 1422 & 1422 \\
\hline cell dimensions & & & \\
\hline$a, b, c(\AA)$ & $149,149,178$ & $149,149,170$ & $149,149,170$ \\
\hline$\alpha, \beta, \gamma($ deg) & $90,90,90$ & $90,90,90$ & $90,90,90$ \\
\hline resolution range $(\AA)$ & $50.0-1.80(1.83-1.80)$ & $50.0-1.68(1.71-1.68)$ & $50.0-1.89(1.92-1.89)$ \\
\hline redundancy & $10.1(8.7)$ & $7.5(5.6)$ & $7.6(5.5)$ \\
\hline completeness $(\%)$ & $98.8(99.8)$ & $99.9(99.3)$ & $99.5(98.9)$ \\
\hline
\end{tabular}




\begin{tabular}{|l|l|l|l|}
\hline no. of unique reflections & 90212 & 107280 & 75403 \\
\hline$R_{\text {merge }}(\%)$ & $7.3(37.6)$ & $7.7(39.8)$ & $7.6(40.0)$ \\
\hline average $I / \sigma$ & $29.5(5.0)$ & $24.2(4.5)$ & $21.5(3.4)$ \\
\hline Refinement & & & \\
\hline resolution range $(\AA)$ & $32.38-1.80(1.85-1.80)$ & $50.0-1.68(1.72-1.68)$ & $50.0-1.89(1.94-1.89)$ \\
\hline$R_{\text {cryst }}$ & $0.147(0.200)$ & $0.169(0.209)$ & $0.170(0.207)$ \\
\hline$R_{\text {free }}$ & $0.171(0.264)$ & $0.193(0.233)$ & $0.198(0.228)$ \\
\hline no. of protein atoms & 5522 & 5974 & 5912 \\
\hline no. of water molecules & 637 & 445 & 504 \\
\hline Wilson $B$ value $\left(\AA^{2}\right)$ & 13.6 & 16.5 & 16.8 \\
\hline average $B$ factor $\left(\AA^{2}\right)$ & & & \\
\hline protein & 19.7 & 16.0 & 17.2 \\
\hline ligands & 23.2 & 31.6 & 18.9 \\
\hline Mg ${ }^{2+}$ & 10.4 & 15.3 & 12.8 \\
\hline solvent & 28.8 & 23.8 & 25.6 \\
\hline Ramachandran plot $(\%)$ & & & 90.9 \\
\hline most favored & 90.8 & 90.7 & 8.4 \\
\hline additionally allowed & 8.4 & 8.7 & 0.3 \\
\hline generously allowed & 0.3 & 0.3 & 0.3 \\
\hline disallowed & 0.5 & 0.3 & 0.013 \\
\hline root-mean-square deviation & & & 1.460 \\
\hline bond lengths $(\AA)$ & 0.017 & 0.014 & \\
\hline bond angles (deg) & 1.754 & 1.553 & \\
\hline
\end{tabular}

avalues in parentheses are for the highest-resolution bin.

\section{Results and Discussion}

\section{Inhibition by Ground State Analogues}

MR binds the enantiomers of mandelate and TFL with similar affinities (Table 2). However, the enzyme binds the enantiomers of lactate with approximately 23 -fold less affinity than it exhibits for mandelate and TFL. This observation indicates that the trifluoromethyl group on the glycolate moiety contributes an additional $\sim 1.8$ $\mathrm{kcal} / \mathrm{mol}$ to the free energy of binding relative to the methyl group. On the basis of the similar binding affinities that MR exhibits for mandelate and TFL, it appears that the binding determinants within the hydrophobic pocket of MR's active site bind the phenyl ring of mandelate and the trifluoromethyl group of TFL with approximately equal affinity. Because MR binds the substrate-product analogue benzilate with an affinity that is similar to that exhibited for mandelate, we hypothesized that MR should bind TFHTP with similar affinity. To our surprise, MR bound TFHTP with an affinity $\left(K_{\mathrm{i}}=27 \mu \mathrm{M}\right)$ that exceeded that exhibited for mandelate and TFL by $\sim 54$-fold (Table 2). The corresponding nonfluorinated analogue, $\alpha$-hydroxyisobutyrate, however, was bound only weakly by $\mathrm{MR}\left(K_{\mathrm{i}}=5.5 \mathrm{mM}\right)$, indicating that the presence of the six fluorine atoms in TFHTP increased the binding affinity by 204 -fold and contributed an additional $3.1 \mathrm{kcal} / \mathrm{mol}$ to the free energy of binding. TFHTP is the most potent ground state analogue inhibitor of MR reported to date, binding with an affinity that is only slightly lower than those reported for the binding of the transition state/intermediate analogues $(R, S)$ - $\alpha$ hydroxybenzylphosphonate $\left(K_{\mathrm{i}}=4.7 \mu \mathrm{M}\right),(25)$ benzohydroxamate $\left(\mathrm{BzH} ; K_{\mathrm{i}}=9.3 \mu \mathrm{M}\right),(25) N$-hydroxyformanilide $\left(K_{\mathrm{i}}=2.8 \mu \mathrm{M}\right),(26)$ and Cupferron $\left(K_{\mathrm{i}}=2.7 \mu \mathrm{M}\right) \cdot(26)$

Table 2. Binding Constants for Substrates, Ground State Analogues, and Transition State Analogues

\begin{tabular}{|l|l|l|l|l|}
\hline $\mathbf{R}^{1} \mathbf{R}^{2} \mathbf{R}^{3} \mathrm{COH}$ & & & & \\
\hline $\mathbf{R}^{1}$ & $\mathbf{R}^{2}$ & $\mathbf{R}^{3}$ & ligand & $K_{\mathrm{i}}(\mathrm{mM}) \mathbf{a}$ \\
\hline
\end{tabular}




\begin{tabular}{|c|c|c|c|c|}
\hline $\begin{array}{l}\text { Substrates and Substrate } \\
\text { Analogues }\end{array}$ & & & & \\
\hline \multirow[t]{2}{*}{$-\mathrm{C}_{6} \mathrm{H}_{5}$} & $-\mathrm{H}$ & $-\mathrm{COO}^{-}$ & $(R)$-mandelate & $1.2 \pm 0.2 b$ \\
\hline & & & (S)-mandelate & $1.0 \pm 0.1 b$ \\
\hline \multirow[t]{2}{*}{$-\mathrm{CF}_{3}$} & $-\mathrm{H}$ & $-\mathrm{COO}^{-}$ & $(R)$-trifluorolactate $[(R)-\mathrm{TFL}]$ & $1.2 \pm 0.2 b$ \\
\hline & & & $(S)$-trifluorolactate $[(S)$-TFL] & $1.74 \pm 0.08 b$ \\
\hline$-\mathrm{COO}^{-}$ & $-\mathrm{H}$ & $-\mathrm{COO}^{-}$ & tartronate & $1.8 \pm 0.1$ \\
\hline \multirow[t]{2}{*}{$-\mathrm{CH}_{3}$} & $-\mathrm{H}$ & $-\mathrm{COO}^{-}$ & $(R)$-lactate & $32.0 \pm 1.4 \mathrm{c}$ \\
\hline & & & $(S)$-lactate & $26.1 \pm 3.1 c$ \\
\hline \multicolumn{5}{|c|}{ Substrate-Product Analogues } \\
\hline$-\mathrm{C}_{6} \mathrm{H}_{5}$ & $-\mathrm{C}_{6} \mathrm{H}_{5}$ & $-\mathrm{COO}^{-}$ & benzilate & $0.67 \pm 0.12 d$ \\
\hline$-\mathrm{CF}_{3}$ & $-\mathrm{CF}_{3}$ & $-\mathrm{COO}^{-}$ & $\begin{array}{l}\text { 3,3,3-trifluoro-2-hydroxy-2- } \\
\text { (trifluoromethyl)propanoate } \\
\text { (TFHTP) }\end{array}$ & $0.027 \pm 0.004$ \\
\hline$-\mathrm{CH}_{3}$ & $-\mathrm{CH}_{3}$ & $-\mathrm{COO}^{-}$ & $\alpha$-hydroxyisobutyrate & $5.5 \pm 0.6$ \\
\hline \multicolumn{5}{|l|}{ Transition State Analogues } \\
\hline$-\mathrm{C}_{6} \mathrm{H}_{5}$ & $-\mathrm{H}$ & $-\mathrm{PO}_{3}^{2-}$ & $\begin{array}{l}(R, S)-\alpha- \\
\text { hydroxybenzylphosphonate }\end{array}$ & $\begin{array}{l}0.0047 \pm 0.0007 \\
\mathrm{e}\end{array}$ \\
\hline$-\mathrm{CF}_{3}$ & $-\mathrm{H}$ & $-\mathrm{PO}_{3}{ }^{2-}$ & $\begin{array}{l}(R, S)-2,2,2 \text {-trifluoro-1- } \\
\text { hydroxyethylphosphonate } \\
\text { (TFHEP) }\end{array}$ & $0.67 \pm 0.13$ \\
\hline$-\mathrm{CH}_{3}$ & $-\mathrm{H}$ & $-\mathrm{PO}_{3}{ }^{2-}$ & $\begin{array}{l}(R, S)-1- \\
\text { hydroxyethylphosphonate (1- } \\
\text { HEP) }\end{array}$ & $40.2 \pm 4.8$ \\
\hline
\end{tabular}

aUnless indicated otherwise, values are competitive inhibition constants. Values are means of triplicate trials, and reported errors are the standard deviations.

${ }^{\mathrm{b}} K_{\mathrm{m}}$ values from ref 4 .

${ }^{\mathrm{C}}$ From ref 5.

${ }^{\mathrm{d}}$ From ref 6.

eFrom ref 25.

\section{Inhibition by Transition State/Intermediate Analogues}

Because trifluoromethyl groups imbued ground state analogues with higher binding affinity, we explored the possibility of incorporating a trifluoromethyl group into the structure of a transition state/intermediate analogue inhibitor. Previously, we demonstrated that $(R, S)$ - $\alpha$-hydroxybenzylphosphonate was a potent inhibitor of MR (Table 2).(25) Therefore, we prepared $(R, S)$-TFHEP as an analogue of the putative aci-carboxylate intermediate formed during the racemization of trifluorolactate.(4) Interestingly, MR bound $(R, S)$-TFHEP with an affinity that was only $\sim 2$-fold greater than the affinity exhibited for TFL (Table 2), in contrast to the $\sim 230$-fold higher affinity exhibited for $(R, S)$ - $\alpha$-hydroxybenzylphosphonate relative to mandelate. Although it appears that, in this case, the trifluoromethyl group does not make a significant contribution to the enhanced binding affinity, such is not the case. First, the overall binding affinity of TFHEP is expected to be reduced relative to that of $\alpha$ hydroxybenzylphosphonate because of the lower transition state stabilization energy afforded by MR during the racemization of the corresponding fluorinated substrate. The transition state stabilization afforded by MR when mandelate is the substrate is $-26 \mathrm{kcal} / \mathrm{mol}$,(2) while the transition state stabilization is reduced to $-20 \mathrm{kcal} / \mathrm{mol}$ when TFL is the substrate.(4) Consequently, one would expect MR to bind a transition state/intermediate analogue based on the structure of the aci-carboxylate of TFL with approximately $2.5 \times 10^{4}$-fold less affinity than it would bind the corresponding transition state/intermediate analogue based on the structure of the acicarboxylate of mandelate. The observed decrease in affinity for $(R, S)$-TFHEP $\left(K_{\mathrm{i}}=0.67 \mathrm{mM}\right)$, relative to that for 
$(R, S)$ - $\alpha$-hydroxybenzylphosphonate $\left(K_{\mathrm{i}}=4.7 \mu \mathrm{M}\right)$, is in accord with this expectation, although the magnitude of the decrease in binding affinity ( 143-fold) is certainly much smaller than expected. Second, the nonfluorinated analogue of $(R, S)$-TFHEP, i.e., $(R, S)$-1-HEP, is bound with an affinity that is 60-fold lower than that exhibited for the corresponding fluorinated intermediate/transition state analogue. Thus, the presence of the trifluoromethyl group in the phosphonate-based transition state/intermediate analogue does enhance binding compared to that observed for the corresponding nonfluorinated analogue. Such enhanced binding arising from substitution of a trifluoromethyl group for a methyl group is not unexpected. For example, $\alpha$-methylacyl-CoA racemase binds the $\alpha$-methyl group of ligands at a hydrophobic pocket within the enzyme's active site, $(27,28)$ and replacement of the $\alpha$-methyl group in $\alpha$-methylmyristoyl-CoA with an $\alpha$-trifluoromethyl group leads to a 152 -fold greater binding affinity.(29)

\section{Sructure of MR Complexed with TFHTP}

The X-ray crystal structure of wild-type MR complexed with TFHTP was determined to $1.68 \AA$ resolution. As with previous crystal structures of MR, the enzyme crystallized in space group 1422 and the asymmetric unit consists of two tightly associating monomers.(7-11) Each monomer of the stable dimer contributes residues to the neighboring active site, and the dimer forms the biologically active octamer through crystallographic symmetry. There are no significant structural changes observed for the ligand-bound structure(8) relative to the ligand-free structure (Figure 1A).

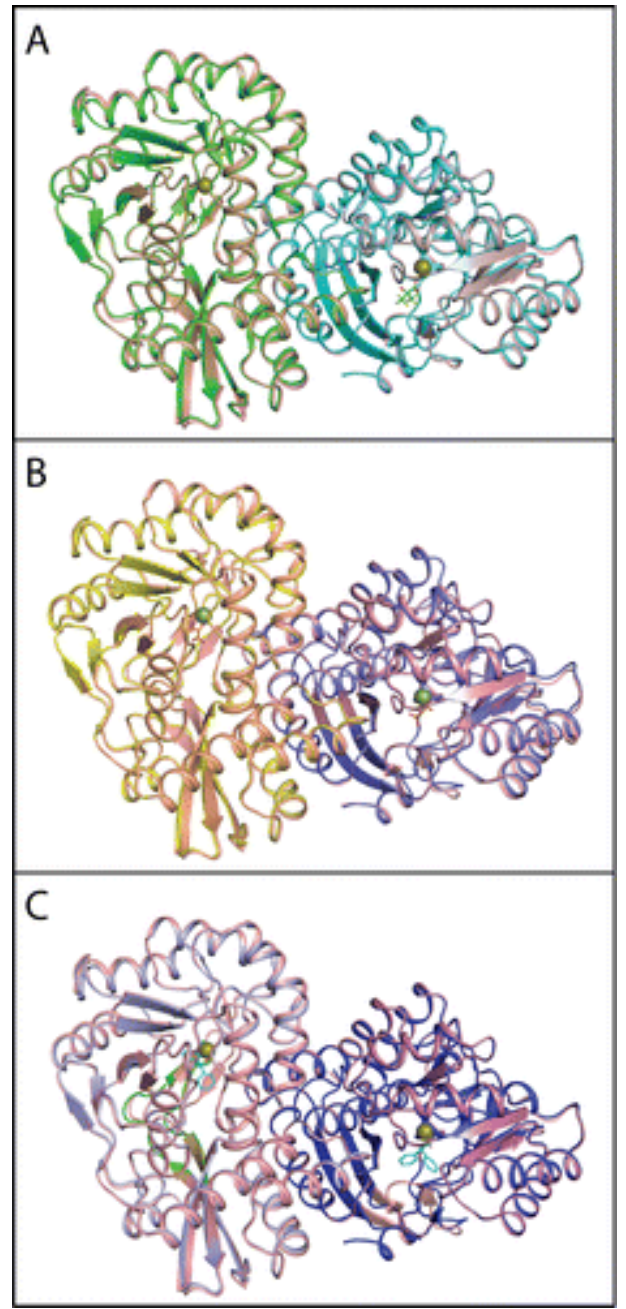

Figure 1. Alignment of the structures of the MR-TFHTP, MR-tartronate, and tmMR-benzilate complexes with ligand-free MR (PDB entry $2 M N R(8)$ ). The structures of the MR-TFHTP (A), MR-tartronate (B), and tmMRbenzilate $(C)$ complexes exhibit no appreciable structural changes with respect to the structure of ligand-free 
MR. The root-mean-square deviation is $0.3 \AA$ upon alignment of the $C \alpha$ atoms of the biological dimer from MRTFHTP (monomer A, green; monomer B, cyan) and MR-tartronate (monomer A, yellow; monomer B, purple) complexes with the equivalent dimer from ligand-free MR (maroon). Alignment of the dimer from the tmMRbenzilate complex (monomer A, light blue; monomer B, blue) with the equivalent dimer from ligand-free MR (maroon) reveals that the 20s loop of the $\mathrm{N}$-terminal capping domain (green) is not closed over the active site. In all structures, the divalent metal ion is shown in space-filling representation (olive) and the ligands are shown in stick representation.

The electron density for the TFHTP ligand varies between active sites, and while both active sites contain acceptable $B$ factors, the electron density for the ligand is most complete for monomer $B$ (Figure $2 A$ ). This discrepancy in ligand binding appears to stem from the inherent disorder associated with a segment of the $\mathrm{N}$ terminal capping domain (Asn 15-Val 35), i.e., the 20s loop, that closes over the active site, constricting the active site cavity and enhancing coordination of the ligand with the metal center.(12) The electron density for the 20 s loop of monomer $A$ is weak relative to that of monomer $B$, and therefore, the observed electron density for TFHTP is more poorly defined in the active site of monomer A. The descriptions of ligand binding are, consequently, limited to the active site of monomer B.

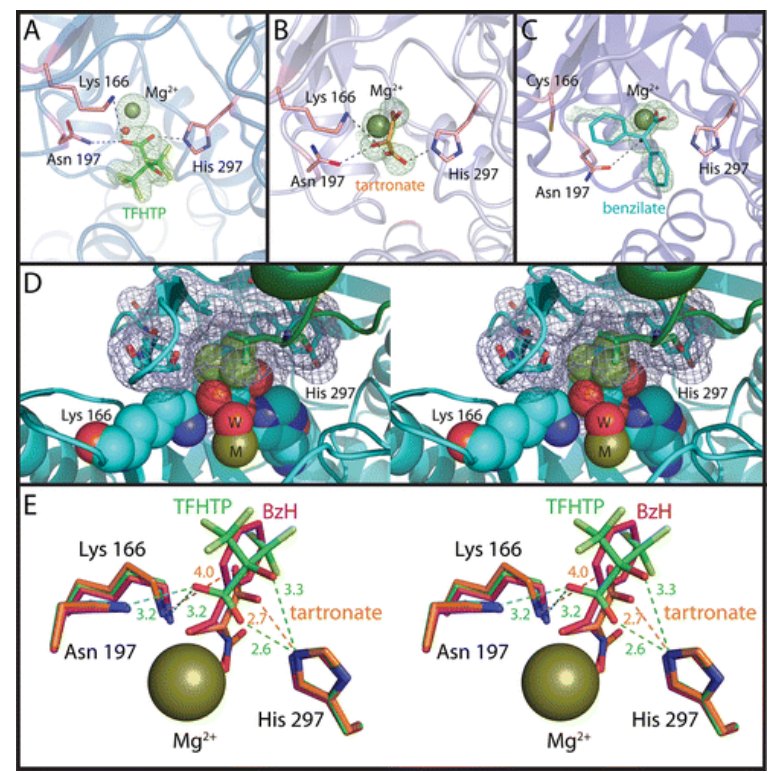

Figure 2. Active site architecture of the MR-TFHTP, MR-benzilate, and tmMR-benzilate complexes. Representative simulated annealing omit maps for the $\mathrm{Mg}^{2+}-\mathrm{TFHTP}(\mathrm{A})$ and $\mathrm{Mg}^{2+}-$ tartronate (B) complexes in the active site of $M R$ and the $\mathrm{Mg}^{2+}$-benzilate complex in tmMR (C) are shown. The electron density maps are contoured at 3.0 $\sigma$ and extend to a distance of $5 \AA$ from the ligand. (D) A stereoview shows the close packing of the trifluoromethyl groups of TFHTP within the hydrophobic cavity of the active site of MR. The two active site Brønsted acid-base catalysts Lys 166 and His 297, $\mathrm{Mg}^{2+}$ (labeled M), water (labeled W), and TFHTP are shown in space-filling representation (with carbon, oxygen, nitrogen, fluorine, and $\mathrm{Mg}^{2+}$ atoms colored cyan, red, blue, "limon", and gray-green, respectively). Hydrophobic residues are shown in stick representation, including Leu 93 from the adjacent subunit within the dimer (green). The purple contour shows the van der Waals surface of the hydrophobic residues. (E) A stereoview shows the superposition of the structures of the MR complexes with bound benzohydroxamate (BzH, purple; PDB entry 3UXK(12)), TFHTP (green), and tartronate (orange). The $\mathrm{Mg}^{2+}$ ion is shown in space-filling representation, while the ligands and Asn 197, His 297, and Lys 166 are shown in stick representation. Putative hydrogen bonds are shown as dashes, and the measurements are in angstroms. 
TFHTP does not bind in the expected "catalytic" orientation, with the glycolate moiety chelating the $\mathrm{Mg}^{2+}$ ion as observed previously in the complexes of MR with (S)-mandelate and $(S)$-atrolactate.(7, 9-11) Instead, TFHTP interacts indirectly with the active site $\mathrm{Mg}^{2+}$ through a bridging water molecule (Figure $2 \mathrm{~A}$ ). The surprisingly high binding affinity of TFHTP must, therefore, arise for reasons other than its ability to chelate the active site metal ion. First, the two trifluoromethyl groups are intimately packed within the hydrophobic pocket, packing against residues of the closed active site flap (Leu 18, Val 22, Thr 24, and Val 29), residues within the $\alpha / \beta$-barrel (Phe 52 and Tyr 54), Leu 298 (on a loop between the strand $\beta 10$ and $\alpha$-helix(8)), residues at the end of the $\beta 11$ strand (Leu 319 and Leu 321), and Leu 93 from the adjacent monomer within the dimer (Figure 2D). Second, the carboxylate group is locked in place by several H-bonds (Figure 2E). Asn 197 and Lys 166 form H-bonds $\sim 3.2 \AA$ in length to one oxygen of the carboxylate. $\mathrm{N} \varepsilon 2$ of His 297 interacts with the other oxygen of the carboxylate group via an $\mathrm{H}$-bond of $2.6 \AA$, and Glu 317 interacts with the same carboxylate oxygen via a bridging water molecule (not shown). Thus, rather than chelating the $\mathrm{Mg}^{2+}$ ion, the carboxylate of TFHTP forms a bridge between the two active site Brønsted acid-base catalysts His 297 and Lys 166. As a consequence of its binding orientation, the carboxylate group assumes a binding orientation such that the plane of the carboxylate group is roughly perpendicular to the orientation of the hydroxamate moiety of BzH (Figure 2E). In addition, NE2 of His 297 interacts with the $\alpha$-OH group of TFHTP via an $\mathrm{H}$-bond of $3.3 \AA$. Considering that the $\mathrm{p} K_{\mathrm{a}}$ of the hydroxyl group of TFHTP should be markedly reduced relative to that of aliphatic alcohols ( $p K_{\mathrm{a}}$ values are 17.1 for 2-

propanol(30) and 9.3 for hexafluoro-2-propanol,(31) bearing in mind that a hydrophobic environment may increase the $\mathrm{p} K_{\mathrm{a}}$ from that expected in aqueous solution), it is plausible that the enhanced binding of TFHTP may also arise, in part, from the transfer of the proton from the hydroxyl group to His 297 . Such a scenario is reminiscent of the time-of-flight neutron structure of the $d$-xylose isomerase-product complex reported by Langan and co-workers(32) in which 05 of $d$-xylulose was not protonated but formed an $\mathrm{H}$-bond (3.07 $\AA$ ) with a doubly protonated His residue. Hence, it is the effect of the optimal hydrophobic packing interactions "pulling" the trifluoromethyl groups of TFHTP toward the active site flap, the steric bulk of the trifluoromethyl groups that resides outside the plane of the phenyl ring of $\mathrm{BzH}$, and the bridging interactions between the active site bases that produce the higher binding affinity of TFHTP even though the glycolate moiety failed to chelate the $\mathrm{Mg}^{2+}$ ion. Consequently, the $\mathrm{Mg}^{2+}$ ion is coordinated by a water molecule (Figure $2 \mathrm{~A}$ ) rather than the $\alpha$-OH group and carboxylate of TFHTP.

\section{Inhibition by Tartronate}

Recognizing that binding of a ligand could be enhanced when a ligand positions a carboxylate between the active site Brønsted acid-base catalysts, we anticipated that tartronate might be an inhibitor of MR. Tartronate is a structural mimic of mandelate in which the glycolate moiety is retained but the phenyl ring is replaced with a carboxylate group (Scheme 1). Interestingly, tartronate inhibited MR with a binding affinity that was similar to that observed for mandelate (Table 2), despite having the polar carboxylate group in place of the nonpolar phenyl ring. In fact, the 15-18-fold difference in binding affinities between lactate and tartronate reveals that the carboxylate group of tartronate contributes an additional $1.7 \mathrm{kcal} / \mathrm{mol}$ in binding energy relative to the methyl group of lactate. This observation suggests that inhibition by tartronate does indeed arise, in part, through interaction of the carboxylate with the active site Brønsted acid-base catalysts.

\section{Structure of MR Complexed with Tartronate}

The X-ray crystal structure of wild-type MR complexed with tartronate was determined to $1.80 \AA$ A resolution. Unlike TFHTP, tartronate is bound in a substratelike orientation, with the glycolate moiety chelating the $\mathrm{Mg}^{2+}$ ion in the active site (Figure 2B). As predicted, the second carboxylate group bridges the two active site Brønsted acid-base catalysts. The carboxylate oxygens of tartronate are positioned $2.7 \AA$ from His 297 and $4.0 \AA$ from Lys 166 (Figure 2E). Interestingly, in all of the ligand-bound structures of MR, Lys 166 assumes an identical rotamer, irrespective of the identity of the bound ligand or the $\mathrm{H}$-bonding potential with different functional groups on 
these ligands (Figure 2E). Nevertheless, the structure supports our hypothesis that the greater than expected binding affinity of tartronic acid results from the interaction of the second carboxylate group with the two Brønsted acid-base catalysts.

While the $\alpha$-carbon of tartronic acid is not a stereogenic center, the electron densities observed for the ligands in monomers $A$ and $B$ of the structure of MR cocrystallized with tartronate suggest that the ligand binds in the active site in two opposing orientations (Figure 3). The bound tartronate in monomer $B$ is best modeled with the $\alpha$-carbon in the position that would be occupied by the $\alpha$-carbon of $(S)$-mandelate, while in monomer $A$, the bound tartronate is best modeled with the $\alpha$-carbon in the position that we anticipate would be occupied by the $\alpha$-carbon of $(R)$-mandelate (Figure $3 \mathrm{~A}, \mathrm{~B})$. The orientation of tartronate in monomer $\mathrm{A}$, therefore, may offer insight into how $(R)$-mandelate is oriented in the active site, because all attempts to cocrystallize MR with $(R)$ mandelate or $(R)$-mandelate analogues have, thus far, been unsuccessful or have caused crystals to crack in soaking-in experiments (unpublished observations). An overlay of chains A and B, centered on the active site, reveals the difference in the $\alpha$-carbon position adopted by tartronate in the two active sites (Figure $3 \mathrm{C}$ ). The difference in the $\alpha$-carbon position is consistent with our previous conclusions that the positions of the functional groups chelating $\mathrm{Mg}^{2+}$ remain relatively fixed during catalysis and that the $\alpha$-carbon and phenyl group move during racemization. $(6,12)$ The two Brønsted acid-base catalysts His 297 and Lys 166 occupy identical positions in these two active sites (Figure $3 \mathrm{C}$ ). However, exclusively in monomer $\mathrm{A}$ where the $\alpha$-carbon of tartronate mimics the $(R)$-mandelate orientation, there are two conformations for the 20s loop that forms part of the hydrophobic cavity within the active site. The 20s loop of monomer A adopts both the open and closed conformations, each at $50 \%$ occupancy, while the 20 s loop in monomer B fully occupies the closed conformation (Figure 3D). The difficulties associated with cocrystallizing and/or soaking the enzyme with $(R)$-mandelate or corresponding analogues suggest that there may be considerable conformational changes associated with the binding of the substrate in the $R$ stereochemistry.

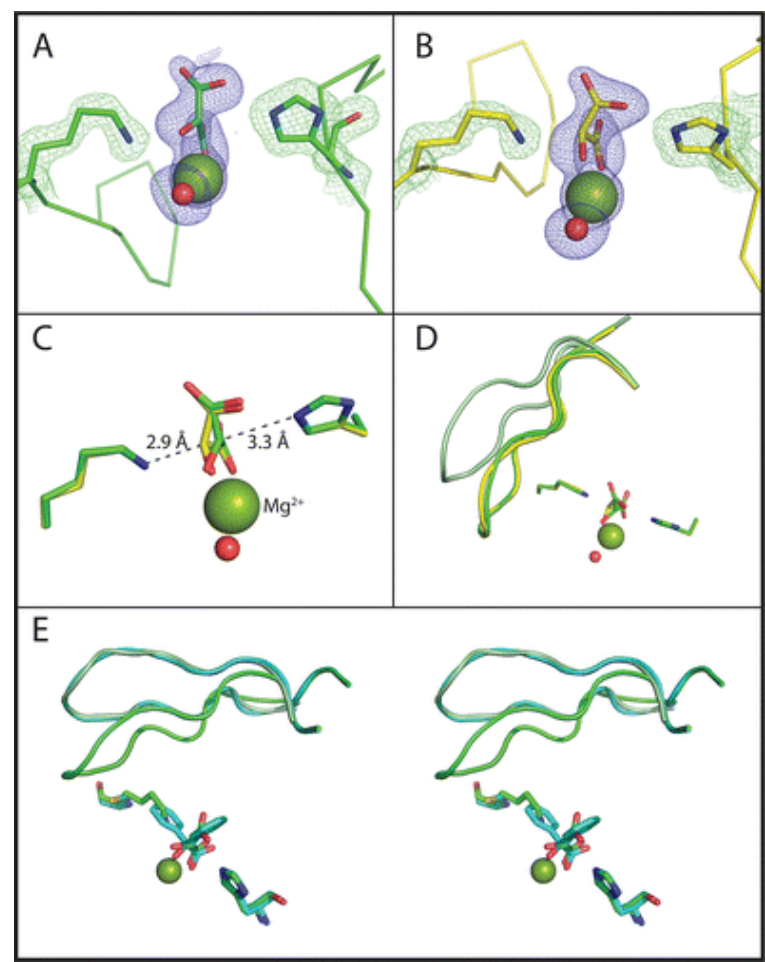

Figure 3. Tartronate and benzilate bound in the active site. Bound tartronate in monomer $A(A)$ and monomer $B$ (B) are shown with electron density maps contoured at $3.0 \sigma$, and extending to a distance of $5 \AA$ from each ligand. The orientation of tartronate in monomer $A$ may mimic that of $(R)$-mandelate, while the orientation of tartronate in monomer B mimics that of (S)-mandelate. (C) An overlay of bound tartronate in monomers $A$ 
(green) and B (yellow), centered on the active site, shows the distances between the $\alpha$-carbon and His 297 and Lys 166, and (D) an expanded view shows the two conformations adopted by the 20s loop upon tartronate binding. In monomer A, the 20s loop adopts both an open (light green) and a closed (green) conformation, while in monomer $B$, the 20s loop has a closed conformation (yellow). (E) A stereoview shows the superposition of the structures of the MR-tartronate (monomer A) and tmMR-benzilate complexes. The 20s loop of the tmMRbenzilate complex (cyan) adopts an open conformation, similar to that of the 20s loop in monomer A of the MRtartronate complex [light green; cf. the closed conformation (green)]. The Brønsted acid-base catalysts Lys 166 and His 297 are shown in stick representation, and $\mathrm{Mg}^{2+}$ (green) and a water molecule (red) are shown in spacefilling representation.

\section{Structure of the tmMR-Benzilate Complex}

As mentioned above, structures of MR with $(R)$-mandelate or $(R)$-mandelate analogues are not yet available; hence, "snapshots" of the entire reaction catalyzed by MR are also not available. We reasoned that benzilate, a substrate-product analogue,(6) might be more amenable to crystallization and would provide insights into the orientation and position of the aromatic rings corresponding to both $(R)$ - and $(S)$-mandelate, recognizing, of course, that the $7.128 \AA$ separation between the para carbon atoms of the phenyl rings observed in the crystal structure of potassium benzilate(33) probably exceeds the distance that the para carbon atom of mandelate moves during MR-catalyzed racemization ( 1.6-2.4 $\AA$ ) and that the ipso carbon remains relatively fixed during MR-catalyzed racemization. $(6,12)$ Unfortunately, despite several cocrystallization and soaking experiments, we were unable to obtain the structure of benzilate within the active site of wild-type MR, possibly because the hydrophobic pocket cannot accommodate two aromatic rings in a conformation that remains amenable to crystallization. However, as part of our ongoing studies of MR, we had prepared the C92S/C264S/K166C triple mutant of MR (tmMR). We anticipated that truncation of the side chain of Lys 166 might afford additional room in the active site, permitting benzilate to bind in a catalytically relevant orientation. The X-ray crystal structure of tmMR complexed with benzilate was determined to $1.89 \AA$ A resolution. As observed for the previously described wild-type structures, tmMR crystallized in space group 1422 with the asymmetric unit consisting of two monomers associating as a biological dimer. The overall structure of tmMR remains largely unperturbed when it is aligned with the ligand-free structure (Figure 1C).

As predicted, the removal of the side chain of Lys 166 in tmMR permitted benzilate to bind in a substratelike orientation similar to that of tartronate and the substrate analogue (S)-atrolactate (Scheme 1),(9) chelating the catalytic $\mathrm{Mg}^{2+}$ ion with the $\alpha$-hydroxyl oxygen and one of the carboxylate oxygens. The 20s loop of the $\mathrm{N}$ terminal capping domain could be modeled for only monomer A because the observed electron density for this region in monomer B was irregular and discontinuous, suggesting multiple conformations. Interestingly, the $20 \mathrm{~s}$ loop of the $\mathrm{N}$-terminal capping domain of monomer A occupies the same open conformation that was observed in monomer $\mathrm{A}$ of the MR-tartronate structure described above (Figures $1 \mathrm{C}$ and $3 \mathrm{E}$ ). Considered together, the structures of MR described in this study suggest that the conformation of the 20s loop depends on two features that are expected to be unique to $(R)$-mandelate: the position of the $\alpha$-carbon and the position of the aromatic ring. Specifically, when a ligand positions its $\alpha$-carbon and $\alpha$-proton like those of $(R)$-mandelate (i.e., tartonate in monomer $\mathrm{A}$ of wild-type $\mathrm{MR}$ ) or its aromatic ring in a position expected to be similar to that of $(R)$-mandelate (i.e., one of the two aromatic rings of benzilate in tmMR), the 20s loop adopts a more open conformation (Figure $3 \mathrm{E}$ ). Thus, the 20 s loop of MR likely undergoes a significant conformational change upon binding $(R)$ mandelate.

\section{Conclusions}

At first blush, it is unlikely that one would conceive of either TFHTP or tartronate as an inhibitor of MR. However, our observations that MR can bind TFL as a substrate with an affinity similar to that exhibited for 
mandelate(4) and that MR is capable of also binding the substrate-product analogue benzilate with a similar affinity(6) led us to anticipate that MR might be inhibited by TFHTP. The fact that TFHTP was bound only 3-fold less tightly than the most potent transition state analogue inhibitors reported to date led us to examine the $\mathrm{X}$ ray crystal structure of the MR-TFHTP complex, which revealed an unexpected binding orientation. The high binding affinity of TFHTP arises from efficient packing of the two trifluoromethyl groups within the hydrophobic pocket of the enzyme's active site and through the participation of the carboxylate group in a bridge between the two active site Brønsted acid-base catalysts His 297 and Lys 166. This observation suggests that inhibitors may be designed to capitalize on the recognition of the active site Brønsted acid-base catalysts as binding determinants, as we showed for tartronate. Consequently, this inhibitor design strategy should allow the development of inhibitors of other enzymes of the enolase superfamily, such as those in the MR, MLE, and MAL subgroups.(34-36)

\section{Accession Codes}

The atomic coordinates of the MR-3,3,3-trifluoro-2-hydroxy-2-(trifluoromethyl)propanoic acid, MR-tartronate, and tmMR-benzilate complexes have been deposited as Protein Data Bank entries $\underline{4 F P 1}, \underline{4 M 6 U}$, and $\underline{4 H N C}$, respectively.

\section{Funding Information}

This work was supported by a Discovery Grant from the Natural Sciences and Engineering Research Council (NSERC) of Canada (S.L.B.) and National Science Foundation MRI-R2 Grant DBI-0959442 (M.St.M.). A.D.L. is supported by a GAANN award (Graduate Assistance in Areas of National Need) from the U.S. Department of Education. Use of the Advanced Photon Source was supported by U.S. Department of Energy, Office of Science, Office of Basic Energy Sciences, under Contract DE-AC02-06CH11357. Use of LS-CAT Sector 21 was supported by the Michigan Economic Development Corp. and the Michigan Technology Tri-Corridor for the support of this research program (Grant 085P1000817).

The authors declare no competing financial interest.

\section{Abbreviations}

\begin{tabular}{|l|l|}
\hline BzH & benzohydroxamate \\
\hline CD & circular dichroism \\
\hline 1-HEP & $(R, S)$-1-hydroxyethylphosphonate \\
\hline HEPES & 4-(2-hydroxyethyl)piperazine-1-ethanesulfonic acid \\
\hline MR & mandelate racemase \\
\hline TFL & trifluorolactate \\
\hline TFHEP & $(R, S)$-2,2,2-trifluoro-1-hydroxyethylphosphonate \\
\hline TFHTP & 3,3,3-trifluoro-2-hydroxy-2-(trifluoromethyl)propanoate. \\
\hline
\end{tabular}

\section{References}

1 Gerlt, J. A. (1998) Enzyme-catalyzed proton transfer reactions to and from carbon. In Bioorganic Chemistry: Peptides and Proteins (Hecht, S. M., Ed.) pp 279-311, Oxford University Press, New York.

2 Bearne, S. L. and Wolfenden, R. (1997) Mandelate racemase in pieces: Effective concentrations of enzyme functional groups in the transition state Biochemistry 36, 1646- 1656

3 St. Maurice, M. and Bearne, S. L. (2002) Kinetics and thermodynamics of mandelate racemase catalysis Biochemistry 41, 4048- 4058 
4 Nagar, M., Narmandakh, A., Khalak, Y., and Bearne, S. L. (2011) Redefining the minimal substrate tolerance of mandelate racemase. Racemization of trifluorolactate Biochemistry 50, 8846-8852

5 St. Maurice, M. and Bearne, S. L. (2004) Hydrophobic nature of the active site of mandelate racemase Biochemistry 43, 2524- 2532

6 Siddiqi, F., Bourque, J. R., Jiang, H., Gardner, M., St. Maurice, M., Blouin, C., and Bearne, S. L. (2005) Perturbing the hydrophobic pocket of mandelate racemase to probe phenyl motion during catalysis Biochemistry 44, 9013-9021

7 Kallarakal, A. T., Mitra, B., Kozarich, J. W., Gerlt, J. A., Clifton, J. G., Petsko, G. A., and Kenyon, G. L. (1995) Mechanism of the reaction catalyzed by mandelate racemase: Structure and mechanistic properties of the K166R mutant Biochemistry 34, 2788- 2797

8 Neidhart, D. J., Howell, P. L., Petsko, G. A., Powers, V. M., Li, R. S., Kenyon, G. L., and Gerlt, J. A. (1991) Mechanism of the reaction catalyzed by mandelate racemase. 2. Crystal structure of mandelate racemase at 2.5-Å resolution: Identification of the active site and possible catalytic residues Biochemistry 30, 9264-9273

9 Landro, J. A., Gerlt, J. A., Kozarich, J. W., Koo, C. W., Shah, V. J., Kenyon, G. L., Neidhart, D. J., Fujita, S., and Petsko, G. A. (1994) The role of lysine 166 in the mechanism of mandelate racemase from Pseudomonas putida: Mechanistic and crystallographic evidence for stereospecific alkylation by (R)- $\alpha$-phenylglycidate Biochemistry 33, 635-643

10 Mitra, B., Kallarakal, A. T., Kozarich, J. W., Gerlt, J. A., Clifton, J. G., Petsko, G. A., and Kenyon, G.

L. (1995) Mechanism of the reaction catalyzed by mandelate racemase: Importance of electrophilic catalysis by glutamic acid 317 Biochemistry 34, 2777- 2787

11 Schafer, S. L., Barrett, W. C., Kallarakal, A. T., Mitra, B., Kozarich, J. W., Gerlt, J. A., Clifton, J. G., Petsko, G. A., and Kenyon, G. L. (1996) Mechanism of the reaction catalyzed by mandelate racemase: Structure and mechanistic properties of the D270N mutant Biochemistry 35, 5662- 5669

12 Lietzan, A. D., Nagar, M., Pellmann, E. A., Bourque, J. R., Bearne, S. L., and St. Maurice, M. (2012) Structure of mandelate racemase with bound intermediate analogues benzohydroxamate and Cupferron Biochemistry 51, 1160- 1170

13 Freeman, S., Irwin, W. J., and Schwalbe, C. H. (1991) Synthesis and hydrolysis studies of phosphonopyruvate J. Chem. Soc., Perkin Trans. 2 263- 267

14 Plaga, W., Frank, R., and Knappe, J. (1988) Catalytic-site mapping of pyruvate formate lyase Eur. J. Biochem. 178, 445- 450

15 Chen, T., Shen, P., Li, Y., and He, H. (2006) The synthesis and herbicidal evaluation of fluorine-containing phenoxyacetoxyalkylphosphonate derivatives Phosphorus, Sulfur Silicon Relat. Elem. 181, 2135- 2145

16 Narmandakh, A. and Bearne, S. L. (2010) Purification of recombinant mandelate racemase: Improved catalytic activity Protein Expression Purif. 69, 39- 46

17 Sharp, T. R., Hegeman, G. D., and Kenyon, G. L. (1979) A direct kinetic assay for mandelate racemase using circular dichroic measurements Anal. Biochem. 94, 329- 334

18 Segel, I. H. (1975) Enzyme Kinetics, John Wiley and Sons, Inc., New York, pp 100-111.

19 Gasteiger, E., Gattiker, A., Hoogland, C., Ivanyi, I., Appel, R. D., and Bairoch, A. (2003) ExPASy: The proteomics server for in-depth protein knowledge and analysis Nucleic Acids Res. 31, 3784- 3788

20 Otwinowski, Z. and Minor, W. (1997) Processing of X-ray diffraction data collected in oscillation mode Methods Enzymol. 276, 307-326

21 McCoy, A. J., Grosse-Kunstleve, R. W., Adams, P. D., Winn, M. D., Storoni, L. C., and Read, R. J. (2007) Phaser crystallographic software J. Appl. Crystallogr. 40, 658-674

22 Emsley, P., Lohkamp, B., Scott, W. G., and Cowtan, K. (2010) Features and development of Coot Acta Crystallogr. D66, 486- 501

23 Vagin, A. A., Steiner, R. S., Lebedev, A. A., Potterton, L., McNicholas, S., Long, F., and Murshudov, G. N. (2004) REFMAC5 dictionary: Organisation of prior chemical knowledge and guidelines for its use Acta Crystallogr. D60, 2284- 2295 
24 Moriarty, N. W., Grosse-Kunstleve, R. W., and Adams, P. D. (2009) Electronic Ligand Builder and Optimization Workbench (eLBOW): A tool for ligand coordinate and restraint generation Acta Crystallogr. D65, 1074- 1080

25 St. Maurice, M. and Bearne, S. L. (2000) Reaction intermediate analogues for mandelate racemase: Interaction between Asn 197 and the $\alpha$-hydroxyl of the substrate promotes catalysis Biochemistry 39, 13324- 13335

26 Bourque, J. R., Burley, R. K., and Bearne, S. L. (2007) Intermediate analogue inhibitors of mandelate racemase: $\mathrm{N}$-Hydroxyformanilide and Cupferron Bioorg. Med. Chem. Lett. 17, 105- 108

27 Bhaumik, P., Schmitz, W., Hassinen, A., Hiltunen, J. K., Conzelmann, E., and Wierenga, R. K. (2007) The catalysis of the 1,1-proton transfer by $\alpha$-methylacyl-CoA racemase is coupled to a movement of the fatty acyl moiety over a hydrophobic, methionine-rich surface J. Mol. Biol. 367, 1145- 1161

28 Sharma, S., Bhaumik, P., Schmitz, W., Venkatesan, R., Hiltunen, J. K., Conzelmann, E., Juffer, A. H., and Wierenga, R. K. (2012) The enolization chemistry of a thioester-dependent racemase: The $1.4 \AA$ crystal structure of a reaction intermediate complex characterized by detailed QM/MM calculations J. Phys. Chem. B 116, 3619- 3629

29 Carnell, A. J., Hale, I., Denis, S., Wanders, R. J., Isaacs, W. B., Wilson, B. A., and Ferdinandusse, S. (2007) Design, synthesis, and in vitro testing of $\alpha$-methylacyl-CoA racemase inhibitors J. Med. Chem. 50, 2700-2707

30 Murto, J. (1964) Nucleophilic reactivity of alkoxide ions toward 2,4-dinitrofluorobenzene and the acidity of alcohols Acta Chem. Scand. 18, 1043- 1053

31 Dyatkin, B. L., Mochalina, E. P., and Knunyants, I. L. (1965) The acidic properties of fluorine-containing alcohols, hydroxylamines and oximes Tetrahedron 21, 2991- 2995

32 Kovalevsky, A. Y., Katz, A. K., Carrell, H. L., Hanson, L., Mustyakimov, M., Fisher, S. Z., Coates, L., Schoenborn, B. P., Bunick, G., Glusker, J. P., and Langan, P. (2008) Hydrogen location in stages of an enzyme-catalyzed reaction: Time-of-flight neutron structure of $d$-xylose isomerase with bound $d$ xylulose Biochemistry 47, 7595- 7597

33 Rojas, L. S., Ramírez, B. M., Mora, A. J., Delgado, G. E., and de Delgado, G. D. (2003) Redetermination of potassium benzilate Acta Crystallogr. E59, m647- m651

$34 \mathrm{Gerlt}$, J. A. and Babbitt, P. C. (2001) Divergent evolution of enzymatic function: Mechanistically diverse superfamilies and functionally distinct suprafamilies Annu. Rev. Biochem. 70, 209- 246

35 Gerlt, J. A., Babbitt, P. C., and Rayment, I. (2005) Divergent evolution in the enolase superfamily: The interplay of mechanism and specificity Arch. Biochem. Biophys. 433, 59- 70

36 Gerlt, J. A., Babbitt, P. C., Jacobson, M. P., and Almo, S. C. (2012) Divergent evolution in the enolase superfamily: Strategies for assigning functions J. Biol. Chem. 287, 29- 34 